\title{
DETERMINATION OF STEPWISE STABILTY CONSTANTS AND GIBB'S FREE ENERGY CHANGE OF TRISPROLINATO COMPLEXES OF SOME DIVALENT TRANSITION METAL IONS
}

\author{
Na'aliya, $\mathrm{J}$. \\ Department of Pure and Industrial Chemistry, Bayero University, Kano \\ e-mail; jnaaliya@yahoo.com
}

\begin{abstract}
The overall stability constants of manganese (II), iron (II), cobalt (II), nickel (II), copper (II), and zinc (II) complexes with proline were determined by potentiometric titration of sodium prolinate with the corresponding salt of the divalent metal in aqueous media. The values of the constants (Logß) were found to be 19.45, 19.23, 19.41, 19.23, 9.76 and 18.51 for manganese (II), iron (II), cobalt (II), nickel (II), Cu (II) and Zn (II) complexes respectively using ORIGIN 50 computational method. The Gibbs free energies of the complexes were found to be in the range of -105.62 to 112.75 for manganese (II), iron (II), cobalt (II), nickel (II), copper (II) and zinc (II) complexes respectively. The values indicate good stability for all the prolinato metal complexes.
\end{abstract}

Keywords: Proline, stability constant, Gibb's free energy, divalent metals and enzymes

\section{INTRODUCTION}

Proline a non essential amino acid is important in maintaining and strengthening of heart muscles (Lehninger, 2000 and Stryer, 1988). It reacts with aqueous sodium hydroxide solution to produce prolinate which has been recognized to form complexes with divalent transition metal ions in aqueous media in which $\mathrm{N}$ and $\mathrm{O}$ donor atoms are incorporated for binding with the metal ion in glycinato way. These compounds are used to explain function of the metals in biological systems because the complexation of the metal ions microcyclic ligands enhances their efficiency in biological processes in the body (Cotton and Wilkinson, 1980 and Satya, 2006). The metal ions and amino acids function better in the form of complexes and the greater the stability the better the efficiency. Recently, there is growing interest to look into thermodynamic parameters of complexation reactions of metal ions and ligands in which the metal - ligand interaction depends on the type of donor atoms, ligand size and complexation bond energies (Amilasan et al., 2010). The presence of nitrogen in the prolinato ligand helps to discriminate metal ions in solution due to its hard and basic properties which show affinity for the transition metals (Amilasan et al., 2010). The investigation of the energetic parameters such as free energy change is very essential in understanding the metal - ligand interaction. The values of Gibb's free energy change $(\Delta G)$ will also be helpful in further understanding the product formation by iron and cobalt which are the main constituents of haemoglobin, and cytochrome in addition to copper and zinc being major components of enzymes. This paper therefore reports the Gibb's free energy change in addition to stability constants of complexes formed by some divalent transition metal cations with prolinato ligands.

\section{MATERIALS AND METHODS}

The pKa of proline was determined as earlier reported (Aliyu and Na'aliya, 2010) by potentiometric titration of $0.1 \mathrm{M}$ sodium hydroxide and $0.08 \mathrm{M}$ proline.

The determination of the stability constant of the complexes was carried out potentiometrically by addition of $0.5 \mathrm{~cm}^{3}$ aliquot of $0.1 \mathrm{M}$ sodium prolinate into a $400 \mathrm{~cm}^{3}$ beaker containing $100 \mathrm{~cm}^{3}$ of 0.04 moldm ${ }^{-3} \mathrm{KNO}_{3}, 10 \mathrm{~cm}^{3}$ of 0.02 moldm $^{-3} \mathrm{HNO}_{3}, 90 \mathrm{~cm}^{3}$ of distilled water and 1millimole (0.001mole) each of the corresponding divalent transition metal salts. The addition of the prolinate solution was continued until $10 \mathrm{~cm}^{3}$ was added and after each addition with stirring the corresponding stable $\mathrm{pH}$ reading was recorded using Jenwey $\mathrm{pH}$ meter model 3320 . The divalent metal salts used include cobalt (II) sulphate, manganese (II) sulphate, iron (II) sulphate and nickel (II) sulphate respectively.

The stepwise and overall stability constants of the complexes were obtained by using 'ORIGIN 50' computational method (Na'aliya, 2008) from the graphs obtained by plotting the values of log $\left[\mathrm{A}^{-}\right]$ versus $n$ developed by Bjerrum (Angelici, 1977). The values of $\left[\mathrm{A}^{-}\right]$(deprotinated amino acid) and $n$ (average number of ligands per metal ion) were calculated from the experimentally known quantities using the expressions ( $\mathrm{i}$ and iv) and (ii and iii) for the constants.

$$
\begin{aligned}
& {\left[\mathrm{A}^{-}\right]=\mathrm{Ka}\left(\mathrm{C}_{\mathrm{H}}-\mathrm{H}^{+}\right] /\left[\mathrm{H}^{+}\right]} \\
& \mathrm{K}_{\mathrm{x}}=1 /\left[\mathrm{A}^{-}\right]_{\mathrm{n}} \text {, where } \mathrm{n}=1 / 2,3 / 2,5 / 2 \ldots \ldots \ldots \ldots \text { (ii) } \\
& \log \beta=\log K_{1}+\log _{2}+\ldots . \log K_{x} \\
& n=\frac{A_{w t^{-}}\left(1+\frac{K a}{M^{+}}\right)\left(C_{H}-\left[O H^{-}\right]-\left[H^{+}\right]\right)}{M_{\text {tot }}}
\end{aligned}
$$


Where $\mathrm{Ka}=$ dissociation constant of the amino acid

$\left[\mathrm{H}^{+}\right]=$concentration of the $\mathrm{H}^{+}$after each aliquot addition

$M_{\text {tot }}=$ total metal ion concentration

$A_{\text {tot }}=$ total amino acid concentration

$\mathrm{n}=$ number of coordinated ligands

$\mathrm{C}_{\mathrm{H}}=$ concentration of nitric acid

$\left[\mathrm{A}^{-}\right]=$concentration of dissociated amino acid

$\mathrm{K}_{\mathrm{x}}=$ stepwise stability constants

$\log \beta=$ overall stability constant

While the standard free energy change $(\Delta G)$ was obtained from the expression

$$
\begin{gathered}
\Delta \mathrm{G}=-2.303 \mathrm{RTLog} \beta \\
\mathrm{R}=\text { Molar gas constant } \\
\mathrm{T}=\text { Kelvin Temperature }
\end{gathered}
$$

\section{RESULTS AND DISCUSSION}

The results obtained (Table 1 ) show the stepwise and overall stability constants to be high indicating good stability of the complexes. In general the stepwise stability constants $\left(\mathrm{K}_{1}\right.$ and $\left.\mathrm{K}_{2}\right)$ follow the order $\mathrm{K}_{1}>\mathrm{K}_{2}$ for the manganese, iron, cobalt, nickel, copper and zinc complexes respectively. The steady decrease of the values with increasing number of ligands is in agreement with the prediction made by Angeleci (1977). The decrease could be attributted to the fact that as the number of the ligands (Prolinate ions) that enters the coordination zone increases the aqua molecules available for replacement by the ligands become less. Thus, the metal ions become less electron loving with progressive intake of the prolinato ligands and this results in the decrease in the values of the constants (Satya et al., 2006; Cotton and Wilkinson, 1980; Angelici, 1977). Also the stability of the complexes is influenced by the size and number of the chelate rings. All the complexes form rings in their structure as prolinate, a bidentate ligand, bound the metal ions in the glycinato way in the ratio $1: 2$ (Sovago et al., 1993) forming chelate rings.

The values of the overall stability constants $(\log \beta)$ obtained for proline complexes are high indicating good stability as the values are high. Similarly, $K_{2}$ value for $\mathrm{Mn}$ - pro complex of 8.91 obtained in this study is higher than those reported for the complexes of Ala, Val and Thr in the range of $6.7-7.7$ (Sovago et al., 1993). The value of $K_{2}$ (9.7) for Co complex reported by Sovago et al (1993) is closer to the values of 8.82 - 9.47 Ala, Val and Thr complexes reported by Berthon (1995) and Sovago et al (1993). But the values are lower than the value of 10.13 reported by Patel (2002) Ni - Thr complex even though both values indicate good stability for the complexes. The difference between the reported values and the values obtained in this study might be probably as a result of temperature difference (for this study $25^{\circ} \mathrm{C}$ ) and computational methods. The values of the constants (Table 1) for the complexes agreed with the Irving William order of stability except the nickel (II) and manganese (II) complexes i.e Fe (II) $=\mathrm{Ni}$ (II) $<\mathrm{Co}$ (II) $<\mathrm{Mn}$ (II) $<\mathrm{Cu}$ (II) $>\mathrm{Zn}$ (II). However the values of the free energy change, $(\Delta G)$ obtained (using equation $v$ ) indicates that all the reactions are feasible and the products (complexes) dominate over the reactants and this is in agreement with the rule of Thumb as all the values are greater than $-60 \mathrm{KJmol}^{-1}$ (Lister and Renshaw, 2000). Also the larger value of energy released is an indication of greater stability of all the complexes (Lister and Renshaw, 2000; Satya et al., 2006; Cotton and Wilkinson, 1980).

The pKa value of 10.53 obtained for proline agrees with the reported values (David and Micheal, 2000 ; Aliyu and Na'aliya, 2010). Also all the complexes formed indicate the number of coordinated ligands (prolinato) to be three and this agreed with the explanation of Sovago et al(1993). The number of the coordinated prolinate was obtained using the expression given by Angelici (1977).

Table 1: Stepwise, Overall Stability constants and Gibb's free energy change of the divalent metal (II) complexes

\begin{tabular}{lcccc}
\hline Complex & Log $_{\mathbf{1}}$ & Log $_{\mathbf{2}}$ & $\mathbf{L o g} \boldsymbol{\beta}$ & $\mathbf{\Delta G}\left(\mathbf{K J m o l}^{\mathbf{- 1}}\right)$ \\
\hline$\left[\mathrm{Mn}(\mathrm{PrO})_{2}\right]$ & 9.73 & 9.9 .72 & 19.45 & -110.98 \\
{$\left[\mathrm{Fe}(\mathrm{PrO})_{2}\right]$} & 9.62 & 9.62 & 19.23 & -109.72 \\
{$\left[\mathrm{Co}(\mathrm{PrO})_{2}\right]$} & 9.71 & 9.70 & 19.41 & -110.75 \\
{$\left[\mathrm{Ni}(\mathrm{PrO})_{2}\right]$} & 9.62 & 9.61 & 19.23 & -109.72 \\
{$\left[\mathrm{Cu}(\text { Pro })_{2}\right]$} & 9.79 & 9.77 & 19.76 & -112.75 \\
{$\left[\mathrm{Zn}(\text { Pro })_{2}\right]$} & 9.27 & 9.24 & 18.51 & -105.62 \\
\hline
\end{tabular}

Key: Pro = prolinate ion, K: stepwise stability constant, Log $\beta$ : overall stability constant, $\Delta \mathrm{G}:$ Gibb's free energy change

\section{CONCLUSION}

The higher values of the overall stability constants and free energy changes of the prolinate metal complexes indicate good stability of the complexes. The larger values of $\Delta G$ also support the complexation of the metal ions with the ligand derived from proline and also indicate the predomination of the products over the reactants. 
The results further indicate the feasibility of the process as the values of $\Delta G$ are all negative. The results also offer part of the reasons why proline and

\section{REFERENCES}

Amilasan, A. T., Solis, J. S., Ario, S. A. and Castriciones, E. V. (2010): Calorimetric Titration of Selected Transition Divalent Metal cations with a Novel Macrocyclic Diamide. Philippine Journal of Science, 139(1):1 - 4.

Aliyu, H. N. and Na'aliya, J. (2010): Determination of Dissociation Constants of Amino acids using 'ORIGIN 50' Program. African Scientist, 11 (1): 5-19.

Angelici, R.J. (1977): Synthesis and techniques in inorganic chemistry W.B. Saunders company, $2^{\text {nd }}$ Edition Philadelphia, Pp $115-127$.

Berthon, G. (1995): The Stability constants of metal complexes of Amino Acids with polar side chains. Pure and Appl. Chem, 67 (7): 1117 1240.

Cotton, F. A. and Wilkinson, G. (1980): Advanced inorganic chemistry, A comprehensive Text, fourth Edition, John Wiley and Sons, New York, Pp 1310 - 1344.

David L. and Micheal M. C. (2000): Lehninger Principles of Biochemistry, Third Edition, worth publishers, 41 Madison Avenue New York, Pp 113 - 158. the metal under study performed their function in body better owing to the stability of the corresponding complexes.

Lister, T. And Renshaw, J. (2000): New Understanding Chemistry for Advanced Level, Third edition. Stanley Thornes publishers. Pp $399-402$.

Na'aliya, J. (2008): Potentiometric studies of some essential metal amino acid complexes. Department of Pure and Industrial Chemistry, Bayero University, Kano, Unpublished PhD thesis.

Patel, R. N., Nripendra, S., Shirivastsava, R. P. Shukla, K. K. and Singh, P. K. (2000): Potentiometric and spectrometric study of copper (II), nickel (II) and zinc (II) complexes with potentially tridentate monodentate lingands. Proceedings Indian Academy Science (Chem Sci.), 114(2): 115124.

Satya, P; Tuli G. D.; Basu S. K. and Madan R. D. (2006): Advanced Inorganic Chemistry Vol. I S. Chand and Company India Pp 705 - 706.

Sovago, I., Kiss, T. and Gergely, A. (1993): Critical survey of the stability constants of complexes of Aliphatic Amino Acids. Pure and Applied Chemistry, 65(5): $1029-1080$.

Stryer, L. (1988): International student Edition Biochemistry, Third Edition W. H. Freeman and Company, NewYork Pp $15-42$. 